\title{
Evaluation of a filter system to harvest plasma for identification of failure of passive transfer in newborn calves
}

\author{
L. da Costa Corrêa Oliveira, ${ }^{1}$ S. Borchardt, ${ }^{1}$ W. Heuwieser, ${ }^{1 *}$ E. Rauch, ${ }^{2}$ M. Erhard, ${ }^{2}$ and F. Sutter ${ }^{1}$ \\ ${ }^{1}$ Clinic for Animal Reproduction, Faculty of Veterinary Medicine, Freie Universität Berlin, Koenigsweg 65, 14163 Berlin, Germany \\ ${ }^{2}$ Department of Veterinary Sciences, Chair of Animal Welfare, Ethology, Animal Hygiene and Animal Husbandry, Faculty of Veterinary Medicine, \\ LMU Munich, Veterinärstraße 13, 80539 Munich, Germany
}

\section{ABSTRACT}

The objective of this study was to evaluate a filter system to harvest plasma to assess failure of passive transfer (FPT) in newborn calves. Blood samples $(\mathrm{n}=$ 227) for serum and plasma harvesting were collected via jugular vein puncture from Holstein calves aged 1 to $7 \mathrm{~d}$ from 4 commercial dairy herds in Northeast Germany. Serum IgG concentrations were determined using a sandwich ELISA. Failure of passive transfer was defined as IgG concentrations $<10 \mathrm{mg} / \mathrm{mL}$ and used as a gold standard. One handheld optical refractometer (Euromex Holland, Arnhem, the Netherlands) and 2 digital Brix refractometers (device 1: HI 96801 digital refractometer, Hanna Instruments, Woonsocket, RI; device 2: Misco PA201, Misco, Solon, OH) were used to analyze total proteins in serum or plasma. The colostrum uptake of the calf can thus be monitored and calves with FPT can be identified. Serum was obtained through centrifugation. Plasma was obtained through either a filter system or centrifugation. For plasma filtration, approximately $2 \mathrm{~mL}$ of lithium heparin blood was injected into the inlet reservoir of a plasma filter (2-Drop-Filter, Pharmadoc, Lübeck, Germany) using a disposable syringe. Receiver operating characteristic curve analyses were used to determine optimum thresholds for each of the 3 devices using different media. Sixty-seven $(30 \%)$ calves had FPT. For the handheld optical refractometer, the optimum threshold was 5.6 $\mathrm{g} / \mathrm{dL}$ [sensitivity $70.1 \%$; specificity $80.0 \%$; positive predictive value (PPV) 60.1\%; negative predictive value (NPV) 86.2\%; area under the curve (AUC) 0.85] using serum. For centrifuged plasma, the optimum threshold was $6.3 \mathrm{~g} / \mathrm{dL}$ (sensitivity $82.1 \%$; specificity $68.1 \%$; PPV 52.5\%; NPV 89.9\%; AUC 0.84), and for filtered plasma, the threshold was $6.0 \mathrm{~g} / \mathrm{dL}$ (sensitivity $56.7 \%$; specificity $90.0 \%$; PPV 70.9\%; NPV 82.9\%; AUC 0.80). For device 1, the optimum threshold was $8.9 \%$ Brix

Received May 3, 2018.

Accepted August 30, 2018.

*Corresponding author: w.heuwieser@fu-berlin.de (sensitivity $82.1 \%$; specificity $63.8 \%$; PPV $48.7 \%$; NPV $89.5 \%$; AUC 0.81 ), $9.4 \%$ Brix (sensitivity $76.1 \%$; specificity 73.7\%; PPV 55.4\%; NPV 87.8\%; AUC 0.80), using serum and centrifuged plasma, respectively. For device 2 , the optimum threshold was $8.7 \%$ Brix (sensitivity $74.6 \%$; specificity $76.2 \%$; PPV $57.4 \%$; NPV $87.5 \%$; AUC 0.83 ), $9.5 \%$ Brix (sensitivity $80.6 \%$; specificity $70.6 \%$; PPV 54.0\%; NPV 89.5\%; AUC 0.83), and 9.2\% Brix (sensitivity $58.2 \%$; specificity $87.5 \%$; PPV $66.6 \%$; NPV 83.0\%; AUC 0.80) using serum, centrifuged plasma, and filtered plasma, respectively. Based on the AUC, the 3 devices yielded comparable test characteristics to identify calves with FPT. In conclusion, a filter system can be used to facilitate the evaluation of FPT as a point of care technique in calves without the need for serum centrifugation.

Key words: plasma filter, failure of passive transfer, colostrum calves

\section{INTRODUCTION}

Management and nutrition of the newborn calf on the first day of life are critically important in optimizing its immunological status and therefore its further health and performance. The quick and adequate intake of high-quality colostrum is essential for delivering sufficient maternal $\mathrm{IgG}$, nutrients, growth factors, and other nonnutrient factors. Insufficient absorption of IgG by the neonatal calf have many negative consequences, such as increased risk of disease and death, slower growth rates, and a reduction in long-term productivity (Robison et al., 1988; DeNise et al., 1989). Furthermore, a quick and adequate colostrum supply has been shown to affect the metabolism and the future performance of the neonatal calf (Faber et al., 2005; Soberon et al., 2012). Inadequate supply of IgG may occur for many reasons, such as timing of the first feeding (Besser et al., 1985), volume of the feeding (Stott et al., 1979), and concentration of IgG in colostrum that was fed (Pritchett et al., 1991).

The paramount role of colostrum for supplying IgG to the neonatal calf has been thoroughly investigated 
and is well documented (Weaver et al., 2000; Godden, 2008). In utero the bovine epitheliochorial placenta prevents the transfer of IgG from the dam to the calf. To acquire immunity, the newborn calf must absorb a critical mass of IgG from colostrum before cessation of intestinal transport occurs at 24 to $36 \mathrm{~h}$ of age (Weaver et al., 2000; Barrington and Parish, 2001). Therefore, it is essential to provide an adequate amount of highquality colostrum during the first $2 \mathrm{~h}$ after birth (Godden, 2008).

Failure of passive transfer (FPT) in calves is defined as serum IgG concentration below $10 \mathrm{mg} / \mathrm{mL}$ (NAHMS, 1993; Weaver et al., 2000; Godden, 2008). The reported prevalence of FPT in other studies ranged from 4.75 to $37.1 \%$ (Wallace et al., 2006; Trotz-Williams et al., 2008; Beam et al., 2009; Morrill et al., 2013; Deelen et al., 2014).

Continuous monitoring of successful passive transfer in newborn calves should be a crucial component of colostrum management (Godden, 2017). Only 6.2\% of US dairy farms routinely monitor FPT on a regular basis (NAHMS, 2014). There are tests available that evaluate serum IgG concentrations, such as radial immunodiffusion (RID) and ELISA, but these tests cannot be considered on farm and are technically demanding and costly (Davis and Giguère, 2005; Hogan et al., 2015). An alternative way to monitor FPT is via an indirect analysis method, the measurement of the total protein (TP) concentration in serum using refractometry (Deelen et al., 2014). Immunoglobulins account for a large part of TP in neonatal calf serum; therefore, refractometry provides an approximation of the serum Ig concentration (Calloway et al., 2002). A handheld optical refractometer can be used for measuring the $\mathrm{TP}$ concentration $(\mathrm{g} / \mathrm{dL})$ in serum, or a digital Brix refractometer can be used to assess the TS percentage in percentage Brix (\% Brix). Both methods are highly correlated with the blood IgG concentration of calves determined by RID. Therefore, these simplified analysis methods allow a good estimation of IgG concentration (Deelen et al., 2014; Buczinski et al., 2018). Calves aged at least $24 \mathrm{~h}$ to $7 \mathrm{~d}$ can be tested (McGuirk and Collins, 2004). Thresholds to define successful passive transfer ranged from 4.6 to $5.8 \mathrm{~g} / \mathrm{dL}$ of $\mathrm{TP}$ in serum (Lee et al., 2008; McCracken et al., 2017) and from 7.1 to $8.8 \%$ Brix measured with a digital Brix refractometer, respectively (Cuttance et al., 2017; McCracken et al., 2017).

For monitoring IgG or TP, it is necessary to separate the serum from the blood cells using a centrifuge. Therefore, its application as an on-farm test is limited. In human medicine, a filter system was developed for point-of-care devices to separate plasma from blood cells. This system was shown to be efficient in separating plasma from cells and has several advantages, such as being portable and quick and requiring only small amounts of blood (Crowley and Pizziconi, 2005; Chen et al., 2009). This method, however, has not been validated for subsequent measurement of $\mathrm{TP}$ via refractometry in veterinary medicine.

The objective of this study was to evaluate a filter system to harvest plasma to assess FPT in newborn calves. We hypothesized that TP measured in filtered plasma using refractometry is highly correlated with serum IgG concentration and serum TP obtained by centrifugation.

\section{MATERIALS AND METHODS}

\section{Animals and Sampling}

The experimental procedures reported herein were conducted with the approval of the Institutional Animal Care and Use Committee of the Freie Universität Berlin. Holstein Friesian calves from 4 commercial dairy herds in Northeast Germany were sampled between August and December 2017. Whole blood was collected from calves $(\mathrm{n}=227) 1$ to $7 \mathrm{~d}$ old by jugular venipuncture using a 20-gauge, 1.5-inch hypodermic needle (Vacutainer, Greiner Bio-One GmbH, Kremesmünster, Austria). Blood was collected into 2 sterile plastic Vacutainer tubes. One tube did not contain any anticoagulant $(8.5 \mathrm{~mL}, \mathrm{BD}$ Vacutainer, Becton Dickinson, Franklin Lakes, NJ), and the other contained lithium heparin (9 mL, Greiner Bio-One GmbH). Samples were stored on ice for transportation to the Freie Universität Berlin.

\section{Filtration and Centrifugation}

Within 4 to $6 \mathrm{~h}$ of collection, serum and heparinized plasma were separated by either centrifugation at $1,500 \times g$ for 6 min at approximately $20^{\circ} \mathrm{C}$ or filtration. For plasma filtration, approximately $2 \mathrm{~mL}$ of lithium heparin blood was injected into the inlet reservoir of a plasma filter (2-Drop-Filter, Pharmadoc, Lübeck, Germany) using a disposable syringe $(12 \mathrm{~mL}$, Henry Schein, Langen, Germany). One filter was used for each measurement, and 2 drops of plasma were obtained per filter. Afterward, the lithium heparin blood samples were centrifuged to obtain plasma. Aliquots of serum and plasma were collected for further analysis using an optical refractometer (handheld refractometer, Euromex Holland, Arnhem, the Netherlands). One milliliter of serum was pipetted into a sterile vial (Cryovial $2 \mathrm{~mL}$, Simport, Bernard-Pilon, Germany) and sent frozen to 
the Department of Veterinary Science, Chair of Animal Welfare, Ethology, Animal Hygiene and Animal Husbandry (Faculty of Veterinary Medicine, LMU Munich, Germany) for IgG testing.

Total protein of serum samples and centrifuged plasma samples was measured by 2 digital Brix refractometers in \% Brix (device 1: HI 96801 digital refractometer, Hanna Instruments, Woonsocket, RI; device 2: Misco PA201, Misco, Solon, OH) and by 1 handheld optical refractometer (Euromex Holland) assessing TP in grams per deciliter to evaluate FPT. Filtered plasma was analyzed with device 2 and the handheld optical refractometer. The measurement with device 1 was not possible because 2 droplets of plasma was not sufficient for the analysis. All 3 refractometers are precision optical devices designed to analyze the concentration of water-soluble solids. They measure the refractive index. The digital Brix refractometers additionally assess the speed at which light passes through the liquid. The denser the liquid, the slower the light passes through it. All devices implement temperature compensation automatically so that an accurate measurement is possible between 0 and $40^{\circ} \mathrm{C}$ for device 1,0 and $50^{\circ} \mathrm{C}$ for device 2 , and 0 and $30^{\circ} \mathrm{C}$ for the handheld refractometer. Calibration was performed with distilled water before each batch of samples.

\section{IgG Analysis}

The IgG analysis in serum measured by sandwich ELISA was conducted at the Department of Veterinary Science, Faculty of Veterinary Medicine, LMU Munich. The sandwich ELISA method was performed according to Erhard et al. (1999) and was based on coating and conjugating the serum IgG with anti-bovine IgG coupled to a peroxidase enzyme (A 5295, SigmaAldrich Chemie GmbH, Taufkirchen, Germany). This peroxidase catalyzed a color change, which was proportional to the IgG concentration of the sample. The quantification was measured photometrically at $450 \mathrm{~nm}$ by an ELISA reader (GENios, Tecan Germany GmbH, Crailsheim, Germany).

Into each well of a 96-well polystyrene plate (F96 Cert. Maxisorp Nunc-Immuno Plate, Thermo Scientific GmbH, Darmstadt, Germany) rabbit serum with antibovine IgG $(5 \mu \mathrm{g} / \mathrm{mL}$; A 5645, Sigma-Aldrich Chemie $\mathrm{GmbH}$ ) was transferred and blocked with a $0.5 \%$ gelatin PBS solution. At the uppermost well of each column, the serum samples were inoculated and diluted with PBS-Tween buffer to obtain $50 \mu \mathrm{L}$ in each well. Furthermore, the peroxidase-linked rabbit anti-bovine IgG was pipetted into each well. The substrate solution $\left[332 \mu \mathrm{L}\right.$ of stock solution, $10 \mathrm{~mL}$ of $3,3^{\prime}, 5,5^{\prime}$-tetra- methylbenzidine (TMB) buffer, $\left.30 \% \mathrm{H}_{2} \mathrm{O}_{2}\right]$ was added, whereby the enzyme reaction took place. By applying $50 \mu \mathrm{L}$ of $1 M$ sulfuric acid, the reaction process was stopped and the photometric intensity was measured. The mean value of each column and thus of each serum sample resulted in the final $\operatorname{IgG}$ concentration (mg of $\operatorname{IgG} / \mathrm{mL})$.

\section{Statistical Analysis}

The TP (in $\mathrm{g} / \mathrm{dL}$ ) and refractometry results (in \% Brix) from centrifuged or filtered plasma were plotted against the $\operatorname{IgG}$ concentration (in $\mathrm{mg} / \mathrm{mL}$ ) in centrifuged serum. From these distribution plots, correlation coefficients (r-values) were determined. The comparison against centrifuged serum was performed only for the handheld optical refractometer and the second digital Brix device (Misco PA201), whereas the comparison against $\operatorname{IgG}$ concentration included all 3 devices. The average (means $\pm \mathrm{SD}$ ) for all the different media and for IgG concentration was calculated using MedCalc software (version 15.6.1, MedCalc, Mariakerke, Belgium). Test characteristics [sensitivity, specificity, positive predictive value (PPV), and negative predictive value (NPV)] were calculated using MedCalc software (version 15.6.1, MedCalc) for all 3 devices and the different media (i.e., centrifuged serum, centrifuged plasma, filtered plasma). Sensitivity was defined as the probability of a test result correctly indicating FPT for a sample with $\operatorname{IgG}<10 \mathrm{mg} / \mathrm{mL}$. Specificity was defined as the probability of a test result correctly indicating adequate passive transfer for a sample with $\operatorname{IgG} \geq 10$ $\mathrm{mg} / \mathrm{mL}$. The PPV was defined as a predictive probability of a test result correctly indicating FPT for a sample with $\operatorname{IgG}<10 \mathrm{mg} / \mathrm{mL}$. The NPV was defined as a predictive probability of a test result correctly indicating adequate passive transfer for a sample with $\operatorname{IgG} \geq 10 \mathrm{mg} / \mathrm{mL}$.

A receiver operating characteristic (ROC) curve was created to plot the true-positive rate against the falsepositive rate at $0.1 \mathrm{~g} / \mathrm{dL}$ and $0.1 \%$ Brix increments, respectively. The critical threshold was assessed with an ROC curve. The point on the curve with the highest combined sensitivity and specificity was considered as the critical threshold. According to Swets (1988) the interpretation of this critical threshold is based on the area under the curve $(\mathbf{A U C})$ as perfect $(\mathrm{AUC}=1)$, highly accurate $(0.9<\mathrm{AUC}<1)$, very accurate $(0.7$ $<$ AUC $<0.9)$, accurate $(0.5<$ AUC $<0.7)$, and noninformative $(\mathrm{AUC}=0.5)$. Variables were declared as significant statistical difference between the levels of a classification when $P<0.05$; a statistical tendency was defined as differences between $P \geq 0.05$ and $P \leq 0.10$. 
Table 1. Descriptive statistics for total protein ( $\mathrm{g} / \mathrm{dL})$, percentage points Brix (\% Brix), and IgG concentration (mg of IgG/mL) considering centrifuged serum, centrifuged plasma, and filtered plasma

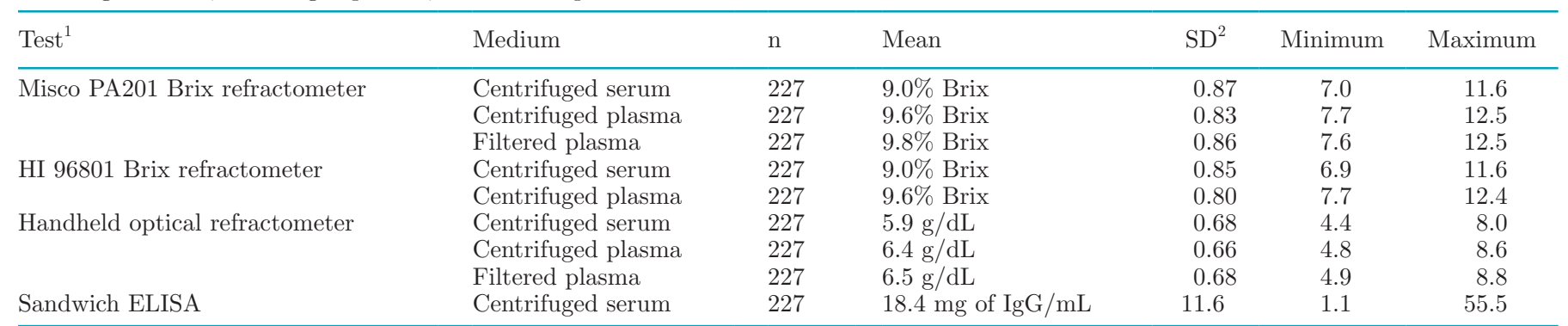

${ }^{1}$ Misco PA201 Brix refractometer: Misco, Solon, Ohio; HI 96801 Brix refractometer: Hanna Instruments, Woonsocket, Rhode Island; handheld optical refractometer: Euromex Holland, Arnhem, the Netherlands.

${ }^{2} \mathrm{SD}=$ standard deviation of the estimate.

\section{RESULTS}

Out of 227 calves, 67 (30\%) had serum IgG concentrations $<10 \mathrm{mg} / \mathrm{mL}$ and $160(70 \%)$ had serum $\operatorname{IgG}$ concentrations $\geq 10 \mathrm{mg} / \mathrm{mL}$. The mean IgG concentration was $18.4 \pm 11.6 \mathrm{mg} / \mathrm{mL}$, and the range was 1.1 to $55.5 \mathrm{mg}$ of $\mathrm{IgG} / \mathrm{mL}$ (Table 1 ).

The mean $\%$ Brix in serum in the present study for device 1 (HI 96801) was $9.0 \pm 0.85 \%$ Brix, and the range was 6.9 to $11.6 \%$ Brix (Table 1). For centrifuged plasma, the mean was $9.6 \pm 0.80 \%$ Brix and the range was 7.7 to $12.4 \%$ Brix. For device 2 (Misco PA201), the mean was $9.0 \pm 0.87 \%$ Brix for serum, $9.6 \pm 0.83 \%$ Brix for centrifuged plasma, and $9.8 \pm 0.86 \%$ Brix for filtered plasma. The assessment via handheld optical refractometer resulted in a mean TP concentration of $5.9 \pm 0.68 \mathrm{~g} / \mathrm{dL}$ in serum, $6.4 \pm 0.66 \mathrm{~g} / \mathrm{dL}$ in centrifuged plasma, and $6.5 \pm 0.68 \mathrm{~g} / \mathrm{dL}$ in filtered plasma. Descriptive statistics for $\%$ Brix and TP in grams per deciliter are summarized in Table 1.

The correlation coefficients and the coefficients of determination are summarized in Figures 1, 2, 3, and 4. The readings from the handheld optical refractometer and the digital refractometer (device 2, Misco PA201) were highly correlated using centrifuged serum, centrifuged plasma, or filtered plasma (Figure 1). The range of correlation coefficients was $\mathrm{r}=0.87$ to 0.92 (Figure 1). The correlation between the $\operatorname{IgG}$ concentration in milligrams per milliliter and the handheld optical refractometer was $\mathrm{r}=0.58$ in serum (Figure 2), $\mathrm{r}=$ 0.51 in centrifuged plasma (Figure 3 ), and $r=0.47$ in filtered plasma (Figure 4). The correlation of $\operatorname{IgG}$ concentration in milligrams per milliliter and device 1 (HI 96801) was $\mathrm{r}=0.50$ (Figure 2) and in centrifuged plasma was $\mathrm{r}=0.43$ (Figure 3 ). Furthermore, the correlation of IgG concentration and device 2 (Misco PA201) was $\mathrm{r}=0.55$ in serum, $\mathrm{r}=0.49$ in centrifuged plasma, and $\mathrm{r}=0.46$ in filtered plasma (Figures 2, 3, and 4).
Test characteristics (optimum thresholds, sensitivity, specificity, PPV, NPV, and AUC) for the handheld optical and digital refractometers to identify calves with FPT using 3 different media were determined by ROC curve analyses (Table 2). For the handheld optical refractometer, the optimum threshold was $5.6 \mathrm{~g} / \mathrm{dL}$ with a sensitivity of $70.1 \%$, specificity of $80.0 \%$, PPV of $60.1 \%$, NPV of $86.2 \%$, and AUC of 0.85 . For device 1 (HI 96801), the optimum threshold using serum was $8.9 \%$ Brix (sensitivity $82.1 \%$, specificity $63.8 \%$, PPV 48.7\%, NPV 89.5\%, AUC 0.81; Table 2). For device 2 (Misco PA201), the optimum threshold measured in serum was $8.7 \%$ Brix (sensitivity $74.6 \%$, specificity $76.2 \%$, PPV $57.4 \%$, NPV $87.5 \%$, AUC 0.83). In general, optimal thresholds for identifying calves with FPT using plasma were greater compared with serum irrespective of the method of plasma harvesting. The 3 different devices had comparable AUC irrespective of the medium used.

\section{DISCUSSION}

The objective of this study was to evaluate a filter system to harvest plasma to assess FPT in newborn calves. We hypothesized that TP and \% Brix measured in filtered plasma using refractometry are highly correlated with serum IgG concentration and therefore suitable for identifying calves with FPT. Thirty percent $(67 / 227)$ of the animals had serum $\operatorname{IgG}<10 \mathrm{mg} / \mathrm{mL}$, representing FPT. The prevalence of FPT in our study was comparable with other studies using the same definition of FPT and similar age of calves (Lee at al., 2008; Morrill et al., 2013; Elsohaby et al., 2015). This study is, however, not representative; hence, the participating farms represent a convenience sample because they were not randomly selected.

The correlation between serum TP and IgG determined by ELISA in our study was lower $(\mathrm{r}=0.58)$ 
a)

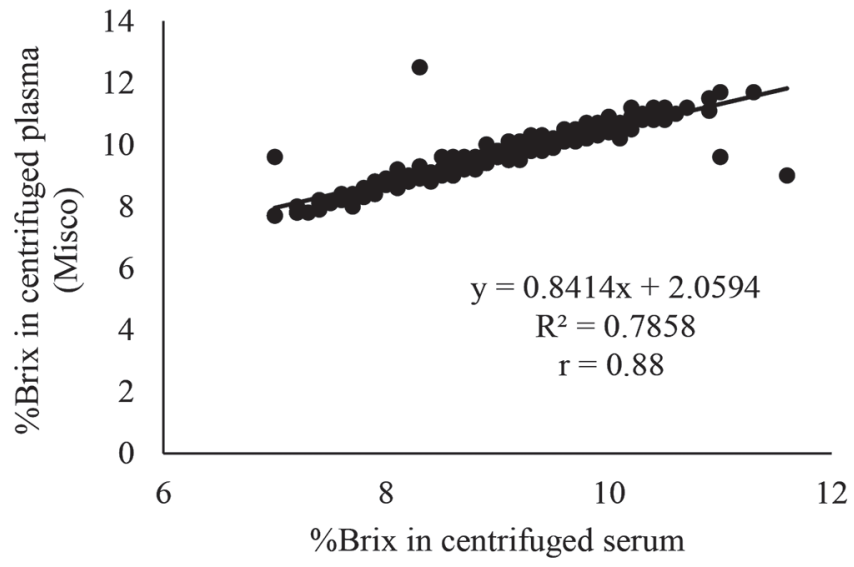

c)

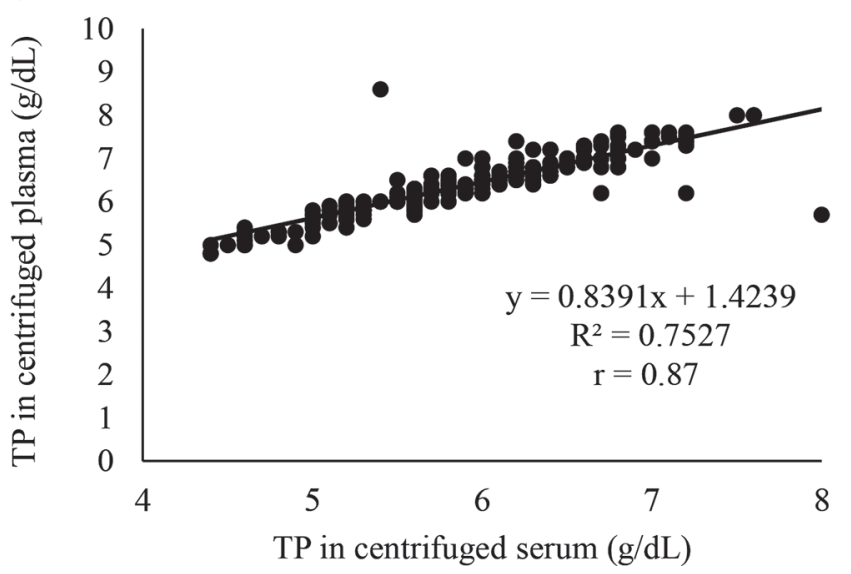

b)

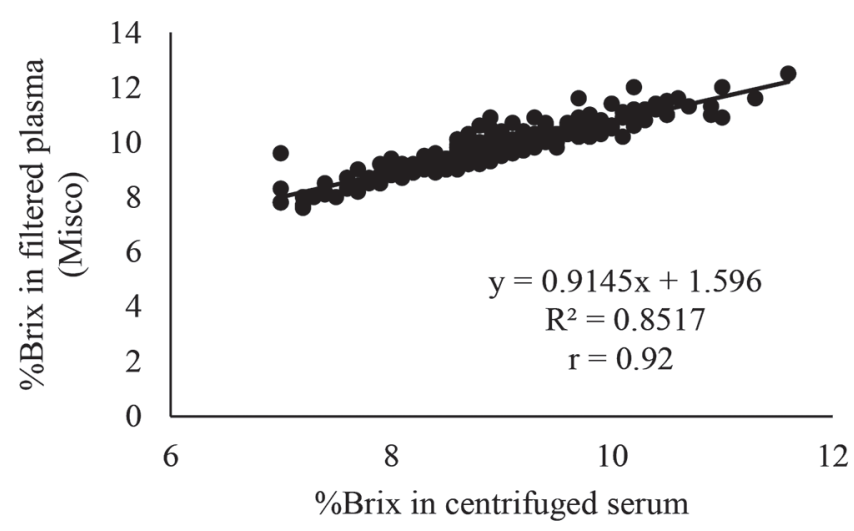

d)

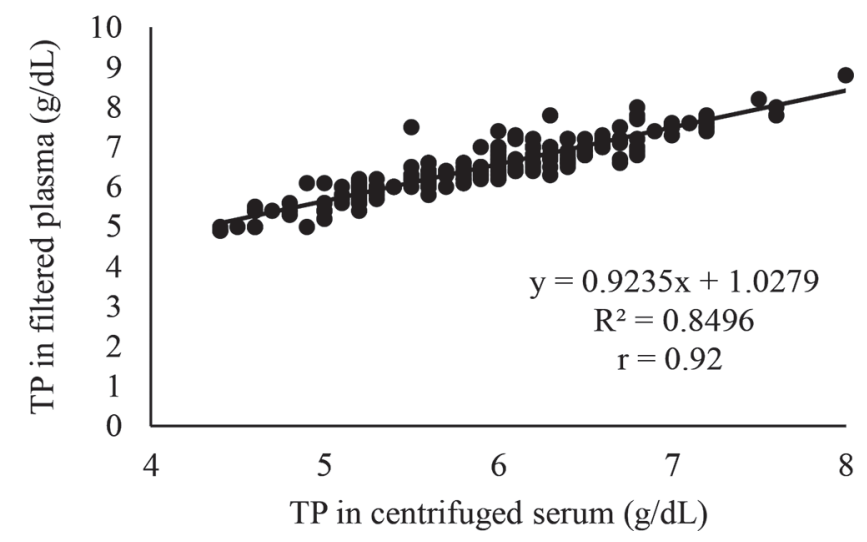

Figure 1. (a) Total protein (TP) concentration in centrifuged serum compared with TP in centrifuged plasma of calves using the Misco PA201 Brix refractometer (Misco, Solon, $\mathrm{OH} ; \mathrm{n}=227 ; \mathrm{r}=0.88$ ); (b) TP concentration in centrifuged serum compared with TP in filtered plasma of calves using the Misco PA201 Brix refractometer $(\mathrm{n}=227 ; \mathrm{r}=0.92) ;(\mathrm{c})$ TP concentration in centrifuged serum compared with TP in centrifuged plasma of calves using the handheld optical refractometer $(\mathrm{n}=227 ; \mathrm{r}=0.87)$; (d) TP concentration in centrifuged serum compared with TP in filtered plasma of calves using the handheld optical refractometer $(\mathrm{n}=227 ; \mathrm{r}=0.92)$. \%Brix $=$ percentage points Brix.

than previously reported (Deelen et al., 2014; Elsohaby et al., 2015; Hernandez et al., 2016; Cuttance et al., 2017). Correlation analysis revealed similar results for $\mathrm{TP}$ in centrifuged $(\mathrm{r}=0.51)$ and filtered $(\mathrm{r}=0.47)$ plasma compared with IgG concentration assessed by sandwich ELISA. Those studies, however, used RID or turbidometric immunoassay for IgG analysis instead of sandwich ELISA. The correlation between \% Brix and IgG determined by sandwich ELISA in our study was also lower (device $1: \mathrm{r}=0.50$; device $2 \mathrm{:} \mathrm{r}=0.55$ ) than in other studies (Morrill et al., 2013; Deelen et al., 2014; Elsohaby et al., 2015; Hernandez et al., 2016; Cuttance et al., 2017). Two recent studies evaluated the agreement between an ELISA and RID to analyze IgG in serum of calves and found only weak to moderate correlations (Gelsinger et al., 2015; Dunn et al., 2018). According to Gelsinger et al. (2015), the concentration of IgG was significantly lower in serum and colostrum samples when measured by ELISA compared with RID, and their study results indicated that the RID is a more consistent method. The cutoff value from RID measurements for successful passive transfer (10 $\mathrm{mg}$ of $\mathrm{IgG} / \mathrm{mL}$ ) was established for serum and plasma samples (Tyler et al., 1996). Gelsinger et al. (2015) referenced that results from ELISA were significantly correlated with RID values, but a direct comparison of ELISA and RID values is not recommended due to a consistent underestimation of IgG concentration by ELISA compared with RID. The authors emphasized that a new threshold should be attributed for ELISA testing to determine FPT in newborn calves.

This might be a reason for the weak association of $\mathrm{TP}$ and \% Brix measured in serum and in centrifuged and filtered plasma compared with serum IgG concentration measured with sandwich ELISA. The results generated in our study by ELISA limit comparability 
with other studies using RID. The single RID measurement includes an agarose gel plate containing antiserum against bovine IgG. The sample spreads from the wells into the agarose gel by diffusion. When antigen and matching antibodies meet, they react with each other and form a precipitate ring. The size of the ring depends on the amount of antigen contained in the solution applied. The diameters of the precipitate rings were measured using a magnifying loupe and were plotted against the IgG concentrations of the standards using linear regression (Dunn et al., 2018). Disadvantages are a low antigen concentration that reduces accuracy and an uneven spread that can confound results. For the comparability and reproducibility of the results, it is crucial to measure the precipitate rings exactly at the same time (Varley et al., 1985). Because the ELISA is similar to RID in accuracy (Weaver et al., 2000), we chose ELISA as the gold standard.

Our methodology, however, does not limit our ability to compare different devices and media using the same gold standard to assess FPT. Moreover, the correlation of the serum $\operatorname{IgG}$ concentration using RID with the serum TP has already been sufficiently investigated and confirmed (Calloway et al., 2002; Moore et al., 2009; Deelen et al., 2014). Using the AUC as an overall indicator of test quality, the results of the 3 different devices and media are comparable because the $95 \%$ confidence interval for the AUC overlap. In addition, there was a high correlation between centrifuged serum and filtered plasma using either the handheld optical a)

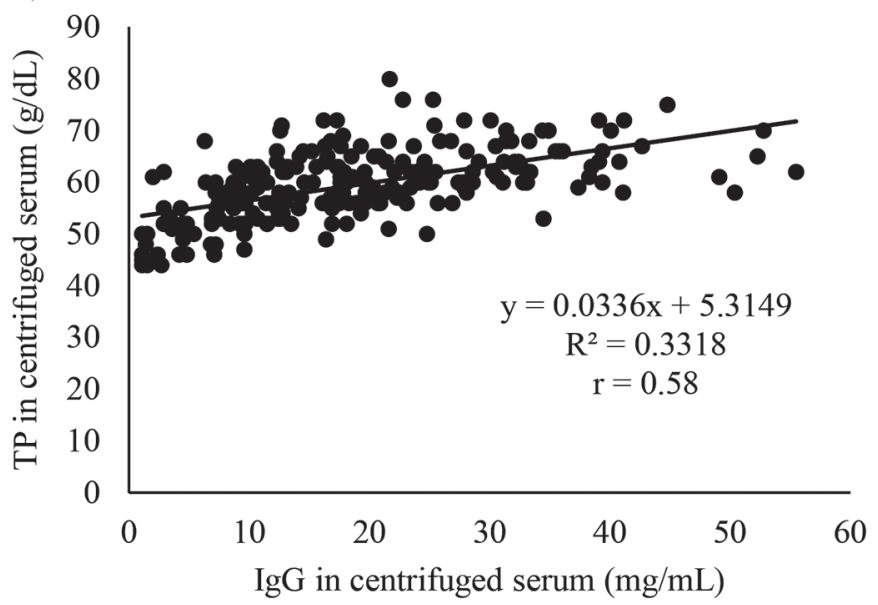

c)

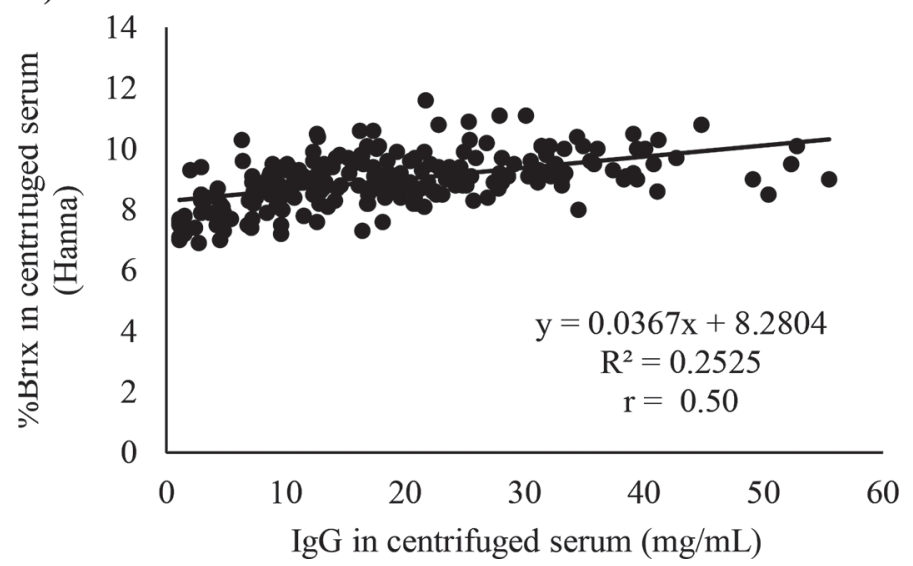

b)

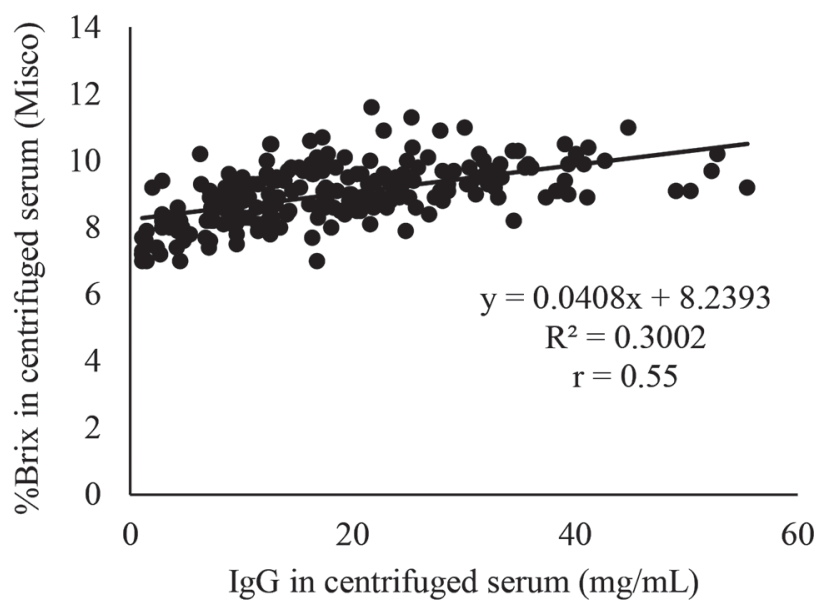

Figure 2. (a) Total protein (TP) concentration in centrifuged serum using the handheld optical refractometer compared with IgG concentration measured by ELISA in centrifuged serum of calves $(\mathrm{n}=227 ; \mathrm{r}=0.58)$; (b) percentage points Brix (\% Brix) using the Misco PA201 Brix refractometer (Misco, Solon, $\mathrm{OH}$ ) in centrifuged serum compared with IgG concentration measured by ELISA in centrifuged serum of calves (n $=227 ; \mathrm{r}=0.55$ ); (c) \% Brix using the HI 96801 Brix refractometer (Hanna Instruments, Woonsocket, OH) in centrifuged serum compared with IgG concentration measured by ELISA in centrifuged serum of calves $(\mathrm{n}=227 ; \mathrm{r}=0.50)$. 
a)

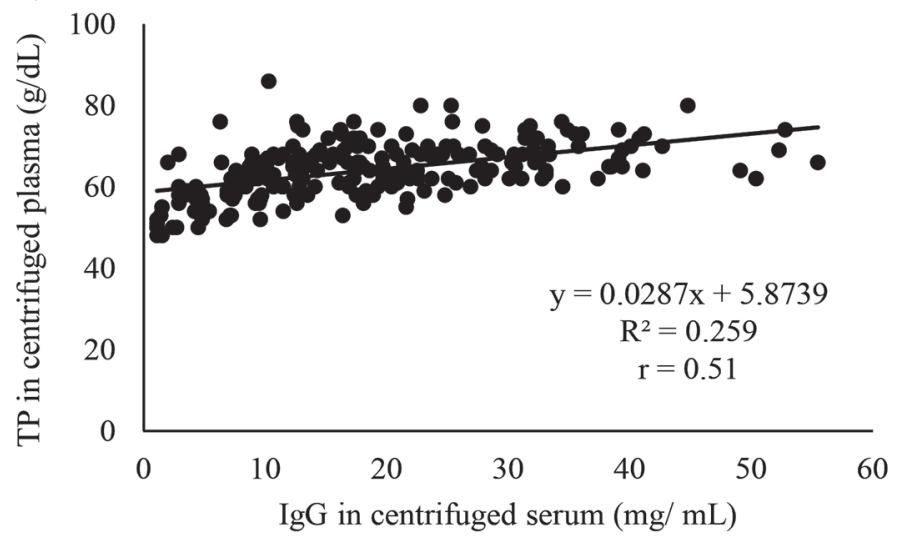

c)

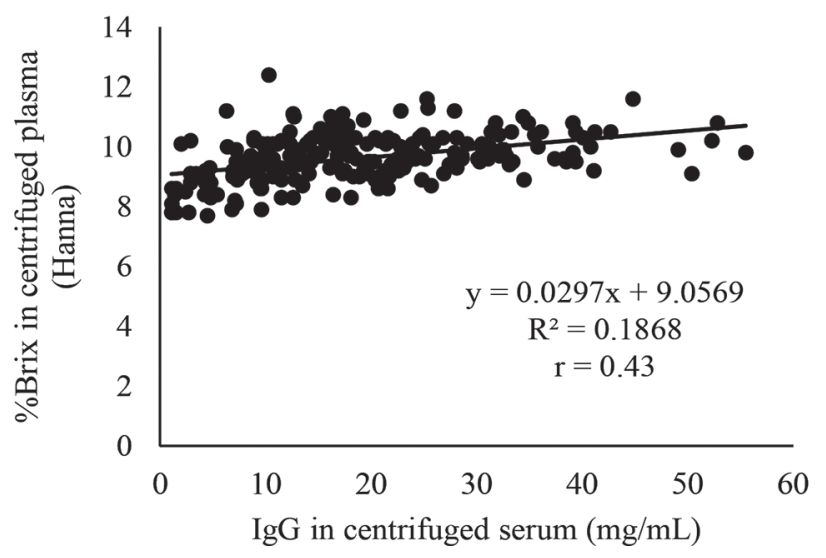

b)

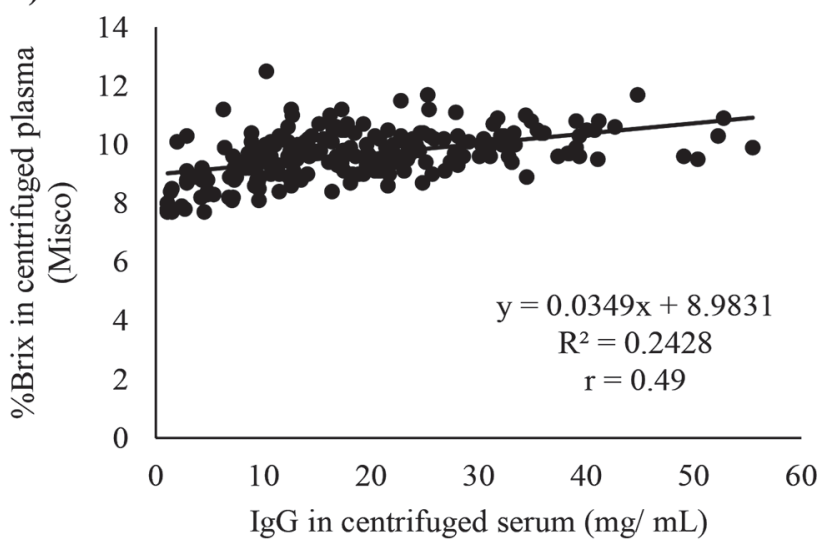

Figure 3. (a) Total protein (TP) concentration in centrifuged plasma using the handheld optical refractometer (Euromex Holland, Arnhem, the Netherlands) compared with IgG concentration measured by ELISA in centrifuged serum of calves $(\mathrm{n}=227 ; \mathrm{r}=0.51)$; (b) percentage points Brix (\% Brix) using the Misco PA201 Brix refractometer (Misco, Solon, OH) in centrifuged plasma compared with IgG concentration measured by ELISA in centrifuged serum of calves $(\mathrm{n}=227 ; \mathrm{r}=0.49)$; (c) \% Brix using the HI 96801 Brix refractometer (Hanna Instruments, Woonsocket, $\mathrm{OH})$ in centrifuged plasma compared with IgG concentration measured by ELISA in centrifuged serum of calves $(\mathrm{n}=227 ; \mathrm{r}=0.43)$.

a)

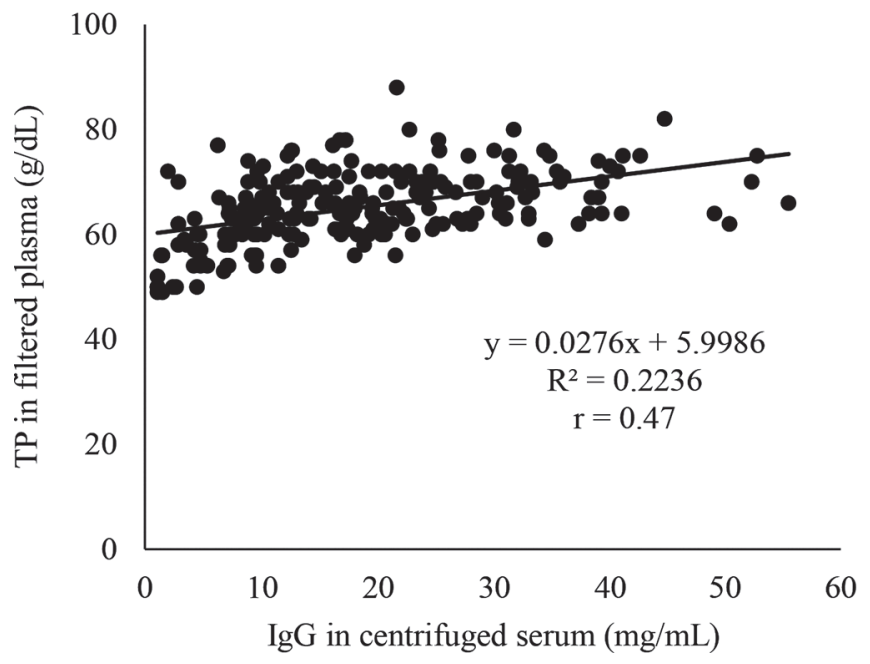

b)

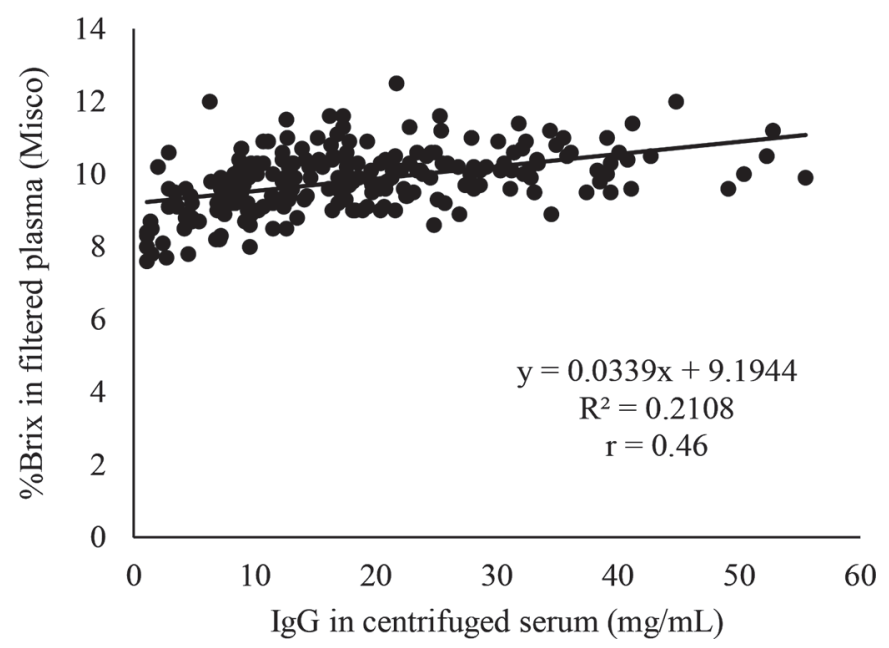

Figure 4. (a) Total protein (TP) concentration in filtered plasma using the handheld optical refractometer (Euromex Holland, Arnhem, the Netherlands) compared with IgG concentration measured by ELISA in centrifuged serum of calves $(\mathrm{n}=227 ; \mathrm{r}=0.47$ ); (b) percentage points Brix (\% Brix) using the Misco PA201 Brix refractometer (Misco, Solon, OH) in filtered plasma compared with IgG concentration measured by ELISA in centrifuged serum of calves $(\mathrm{n}=227 ; \mathrm{r}=0.46)$. 


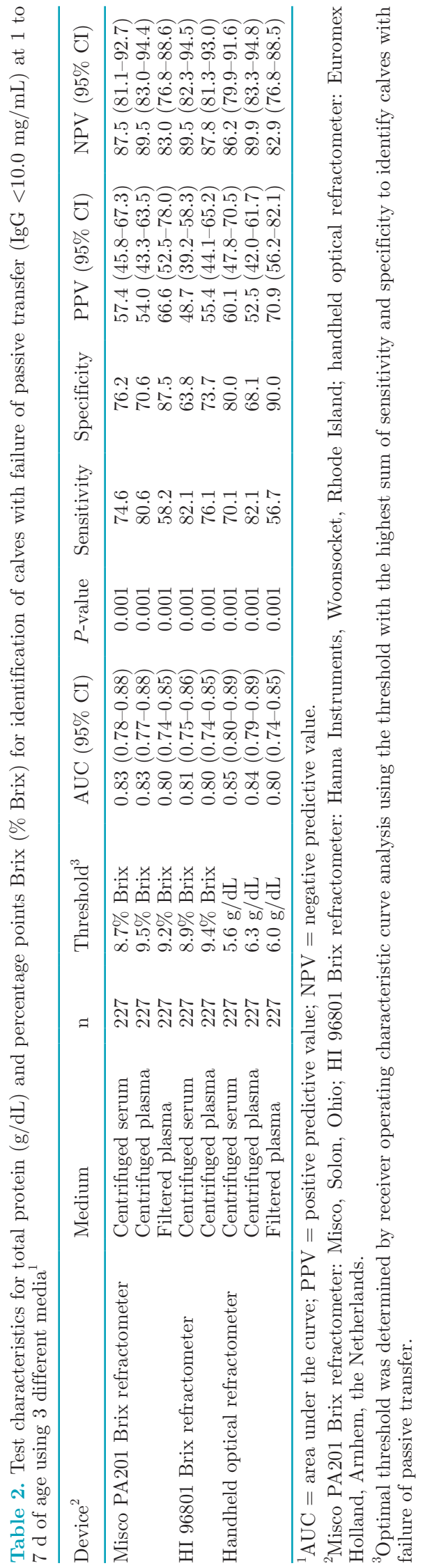

refractometer or the digital Brix refractometer. These high correlations indicate that filtered and centrifuged plasma are well suited for determining FPT in calves.

The AUC was used as an overall indicator of test characteristics irrespective of the device or the medium and ranged from 0.8 to 0.85 in our study. The results, independent of the device or the medium, proved to be very accurate $(0.7<\mathrm{AUC}<0.9$; Swets, 1988). This is comparable with other studies using a handheld optical refractometer (Lee et al., 2008; Elsohaby et al., 2015; Hernandez et al., 2016; Cuttance et al., 2017) or a digital Brix refractometer (Morrill et al., 2013; Elsohaby et al., 2015; Hernandez et al., 2016; Cuttance et al., 2017) to assess FPT in calves.

The optimum threshold in our study for identifying calves with FPT using serum TP was $5.6 \mathrm{~g} / \mathrm{dL}$ and $8.7 \%$ Brix, and $8.9 \%$ Brix for devices 1 and 2, respectively. This is comparable with other studies (Lee et al., 2008; Elsohaby et al., 2015; Hernandez et al., 2016; Cuttance et al., 2017) using serum IgG concentration as a gold standard to define FPT and an ROC curve analysis to determine the best threshold. Using $5.6 \mathrm{~g} / \mathrm{dL}$ as the threshold, sensitivity was $70.1 \%$, specificity was $80.0 \%$, PPV was $60.1 \%$, and NPV was $86.2 \%$. This is in line with a recent meta-analysis (Buczinski et al., 2018) in which sensitivity and specificity were 88.2 and $77.9 \%$, respectively, using $5.5 \mathrm{~g} / \mathrm{dL}$ as a threshold in a population of calves under $14 \mathrm{~d}$ of age. However, Elsohaby et al. (2015) and Cuttance et al. (2017) reported greater overall test characteristics $(\mathrm{AUC}=0.90$, Elsohaby et al., 2015; AUC $=0.95$, Hernandez et al., 2016; AUC = 0.94, Cuttance et al., 2017) compared with our study $(\mathrm{AUC}=0.85$ for handheld optical refractometer, 0.81 for device 1 , and 0.83 for device 2 ). The reason for this difference remains speculative.

The PPV ranged from 48.7 to $70.9 \%$ considering different media and devices and a prevalence of $30 \%$ FPT. This might lead to overdiagnosing FPT. In filtered plasma the sensitivity was lower $(56.7 \%$ for handheld optical refractometer; $58.2 \%$ for device 2 ) than in centrifuged plasma or serum. The reason for this difference remains again speculative and requires further research. Specific thresholds, however, for serum and plasma have to be used. In general, thresholds for plasma were higher compared with serum, most likely because of the presence of coagulation proteins in plasma, which are missing in serum. Fibrinogen represents a part of the protein fraction, which is captured during clotting (Lumeij and Maclean, 1996).

\section{CONCLUSIONS}

In conclusion, a filter system to facilitate FPT assessment as a point-of-care analysis in calves without the 
need to centrifuge serum would be beneficial for dairy farms because of the easy handling and cost reduction. This study is the first to report an approach that allows omitting centrifugation, a costly and impractical method for dairy farms limiting the ability to use TP or \% Brix as a calf-side test. To recommend this filter system as a point-of-care system, further research is warranted.

\section{ACKNOWLEDGMENTS}

We gratefully thank the participating dairy farms for their collaboration. L. da Costa Corrêa Oliveira was funded by a scholarship from the Erasmus Program of the European Commission. The authors thank Pharmadoc (Lübeck, Germany) and TaiDoc (New Taipei City, Taiwan) for providing the plasma filters as well as MSD (Haar, Germany) for the laboratory cost support and Dairytop (Beilen, the Netherlands) for providing the Misco (Misco, Solon, OH) Brix refractometer.

\section{REFERENCES}

Barrington, G. M., and S. M. Parish. 2001. Bovine neonatal immunology. Vet. Clin. North Am. Food Anim. Pract. 17:463-476. https:/ /doi.org/10.1016/S0749-0720(15)30001-3.

Beam, A. L., J. E. Lombard, C. A. Kopral, L. P. Garber, A. L. Winter, J. A. Hicks, and J. L. Schlater. 2009. Prevalence of failure of passive transfer of immunity in newborn heifer calves and associated management practices on US dairy operations. J. Dairy Sci. 92:3973-3980.

Besser, T. E., A. E. Garmedia, T. C. McGuire, and C. C. Gay. 1985. Effect of colostral immunoglobulin G1 and immunoglobulin M concentrations on immunoglobulin absorption in calves. J. Dairy Sci. 68:2033-2037.

Buczinski, S., E. Gicquel, G. Fecteau, Y. Takwoingi, M. Chigerwe, and J. M. Vandeweerd. 2018. Systematic review and meta-analysis of diagnostic accuracy of serum refractometry and Brix refractometry for the diagnosis of inadequate transfer of passive immunity in calves. J. Vet. Intern. Med. 32:474-483.

Calloway, C. D., J. W. Tyler, R. K. Tessman, D. Hostetler, and J. Holle. 2002. Comparison of refractometers and test endpoints in the measurement of serum protein concentration to assess passive transfer status in calves. J. Am. Vet. Med. Assoc. 221:1605-1608.

Chen, X., D. Cui, and J. Chen. 2009. Design, fabrication, characterization of nano-filters in silicon microfluidic channels based on MEMS technology. Electrophoresis 30:3168-3173. https://doi.org/ 10.1002/elps.200900068.

Crowley, T. A., and V. Pizziconi. 2005. Isolation of plasma from whole blood using planar microfilters for lab-on-a-chip application. Lab Chip 5:922-929. https://doi.org/10.1039/b502930a.

Cuttance, E. L., W. A. Mason, K. S. Denholm, and R. A. Laven. 2017. Comparison of diagnostic tests for determining the prevalence of failure of passive transfer in New Zealand dairy calves. N. Z. Vet. J. 65:6-13. https://doi.org/10.1080/00480169.2016.1230525.

Davis, R., and S. Giguère. 2005. Evaluation of five commercially available assays and measurement of serum total protein concentration via refractometry for the diagnosis of failure of passive transfer of immunity in foals. J. Am. Vet. Med. Assoc. 227:1640-1645.

Deelen, S. M., T. L. Ollivett, D. M. Haines, and K. E. Leslie. 2014. Evaluation of a Brix refractometer to estimate serum immunoglobulin G concentration in neonatal dairy calves. J. Dairy Sci. 97:3838-3844.
DeNise, S. K., J. D. Robison, G. H. Stott, and D. V. Armstrong. 1989. Effects of passive immunity on subsequent production in dairy heifers. J. Dairy Sci. 72:552-554.

Dunn, A., C. Duffy, A. Gordon, S. Morrison, A. Argüello, M. Welsh, and B. Earley. 2018. Comparison of single radial immunodiffusion and ELISA for the quantification of immunoglobulin $\mathrm{G}$ in bovine colostrum, milk and calf sera. J. Appl. Anim. Sci. 46:758-765. https://doi.org/10.1080/09712119.2017.1394860.

Elsohaby, I., J. T. McClure, and G. P. Keefe. 2015. Evaluation of digital and optical refractometers for assessing failure of transfer of passive immunity in dairy calves. J. Vet. Intern. Med. 29:721-726.

Erhard, M. H., P. Amon, S. Nüske, and M. Stangassinger. 1999. Studies on the systemic availability of maternal and endogeneously produced immunoglobulin G1 and G2 in newborn calves by using newly developed ELISA systems. J. Anim. Physiol. Anim. Nutr. (Berl.) 81:239-248.

Faber, S. N., N. E. Faber, T. C. McCauley, and R. L. Ax. 2005. Case study: Effects of colostrum ingestion on lactational performance. Prof. Anim. Sci. 21:420-425.

Gelsinger, S. L., A. M. Smith, C. M. Jones, and A. J. Heinrichs. 2015. Technical note: Comparison of radial immunodiffusion and ELISA for quantification of bovine immunoglobulin $\mathrm{G}$ in colostrum and plasma. J. Dairy Sci. 98:4084-4089. https://doi.org/10.3168/jds .2014-8491.

Godden, S. 2008. Colostrum management for dairy calves. Vet. Clin. North Am. Food Anim. Pract. 24:19-39.

Godden, S. 2017. Management of the newborn calf. Pages 399-408 in Large Dairy Herd Management. 3rd ed. D. K. Beede, ed. American Dairy Science Association, Champaign, IL.

Hernandez, D., D. V. Nydam, S. M. Godden, L. S. Bristol, A. Kryzer, J. Ranum, and D. Schaefer. 2016. Brix refractometry in serum as a measure of failure of passive transfer compared to measured immunoglobulin $\mathrm{G}$ and total protein by refractometry in serum from dairy calves. Vet. J. 211:82-87. https://doi.org/10.1016/j.tvjl.2015 .11 .004 .

Hogan, I., M. Doherty, J. Fagan, E. Kennedy, M. Conneely, P. Brady, C. Ryan, and I. Lorenz. 2015. Comparison of rapid laboratory tests for failure of passive transfer in the bovine. Ir. Vet. J. 68:18. https://doi.org/10.1186/s13620-015-0047-0.

Lee, S. H., J. Jaekal, C. S. Bae, B. H. Chung, S. C. Yun, M. J. Gwak, G. J. Noh, and D. H. Lee. 2008. Enzyme-linked immunosorbent assay, single radial immunodiffusion, and indirect methods for the detection of failure of transfer of passive immunity in dairy calves. J. Vet. Intern. Med. 22:212-218. https://doi.org/10.1111/j.1939 $-1676.2007 .0013 . x$.

Lumeij, J. T., and B. Maclean. 1996. Total protein determination in pigeon plasma and serum: Comparison of refractometric methods with the biuret method. J. Avian Med. Surg. 10:150-152.

McCracken, M. M., K. M. Morrill, A. L. Fordyce, and H. D. Tyler. 2017. Technical note: Evaluation of digital refractometers to estimate serum immunoglobulin $\mathrm{G}$ concentration and passive transfer in Jersey calves. J. Dairy Sci. 100:8438-8442. https://doi.org/10 $.3168 /$ jds.2017-12847.

McGuirk, S. M., and M. Collins. 2004. Managing the production, storage, and delivery of colostrum. Vet. Clin. North Am. Food Anim. Pract. 20:593-603. https://doi.org/10.1016/j.cvfa.2004.06.005.

Moore, D. A., J. Taylor, M. L. Hartman, and W. M. Sischo. 2009. Quality assessments of waste milk at a calf ranch. J. Dairy Sci. 92:3503-3509.

Morrill, K. M., J. Polo, A. Lago, J. Campbell, J. Quigley, and H. Tyler. 2013. Estimate of serum immunoglobulin G concentration using refractometry with or without caprylic acid fractionation. J. Dairy Sci. 96:4535-4541. https://doi.org/10.3168/jds.2012-5843.

National Animal Health Monitoring System. 1993. National Dairy Heifer Evaluation Project: Dairy Herd Management Practices Focusing on Preweaned Heifers. USDA-APHIS Veterinary Services, Fort Collins, CO.

National Animal Health Monitoring System. 2014. Dairy Cattle Management Practices in the United States. USDA-APHIS Veterinary Services, Fort Collins, CO. 
Pritchett, L. C., C. C. Gay, T. E. Besser, and D. D. Hancock. 1991. Management and production factors influencing immunoglobulin G1 concentration in colostrum from Holstein cows. J. Dairy Sci. 74:2336-2341.

Robison, J. D., G. H. Stott, and S. K. DeNise. 1988. Effects of passive immunity on growth and survival in the dairy heifer. J. Dairy Sci. 71:1283-1287.

Soberon, F., E. Raffrenato, R. W. Everett, and M. E. van Amburgh. 2012. Preweaning milk replacer intake and effects on long-term productivity of dairy calves. J. Dairy Sci. 95:783-793. https://doi .org/10.3168/jds.2011-4391.

Stott, G. H., D. B. Marx, B. E. Menefee, and G. T. Nightengale. 1979. Colostral immunoglobulin transfer in calves I. Period of absorption. J. Dairy Sci. 62:1632-1638. https://doi.org/10.3168/jds .S0022-0302(79)83472-4.

Swets, J. A. 1988. Measuring the accuracy of diagnostic systems. Science 240:1285-1293. https://doi.org/10.1126/science.3287615.
Trotz-Williams, L. A., K. E. Leslie, and A. S. Peregrine. 2008. Passive immunity in Ontario dairy calves and investigation of its association with calf management practices. J. Dairy Sci. 91:3840-3849.

Tyler, J. W., D. D. Hancock, S. M. Parish, D. E. Rea, and T. E. Besser. 1996. Evaluation of 3 assays for failure of passive transfer in calves. J. Vet. Intern. Med. 10:304-307.

Varley, M. A., G. J. Rucklidge, R. J. Wilkinson, and A. Maitland. 1985. Enzyme-linked immunosorbent assay for the measurement of immunoglobulin $\mathrm{G}$ concentrations in porcine plasma and colostrum. Res. Vet. Sci. 38:279-281.

Wallace, M. M., B. D. Jarvie, N. R. Perkins, and K. E. Leslie. 2006. A comparison of serum harvesting methods and type of refractometer for determining total solids to estimate failure of passive transfer in calves. Can. Vet. J. 47:573-575.

Weaver, D. M., J. W. Tyler, D. C. VanMetre, D. E. Hostetler, and G. M. Barrington. 2000. Passive transfer of colostral immunoglobulins in calves. J. Vet. Intern. Med. 14:569-577. 